\title{
Metabolismo lipídico da raia vivípara Potamotrygon falkneri Castex \& Maciel, 1963 durante a reprodução
}

Mudanças sazonais na composição corporal têm sido observadas em várias espécies de vertebrados, e estas alterações parecem estar relacionadas com a vitelogênese, bem como outros processos associados com a desova, transferência materno-fetal e sobrevida da prole. No caso de arraias certamente a distribuição metabólica e compromisso de reservas energéticas para a reprodução se estenderá a períodos pós-vitelogênicos, já que o sucesso reprodutivo destas espécies dependerá do desenvolvimento do trofonema e do leite uterino, que servirão de base nutritiva para os embriões até o momento do parto. O objetivo deste trabalho foi investigar o padrão de armazenamento, mobilização e utilização de substratos lipídicos e ácidos graxos envolvida com a reprodução da espécie Potamotrygon falkneri em diferentes fases do ciclo reprodutivo. Os animais coletados foram anestesiados e eutanasiados, com posterior extração e determinação da concentração de lipídeos totais e perfil de ácidos graxos dos tecidos hepático, muscular, ovariano e uterino. Após as coletas e análise macroscópica dos ovários os animais determinação da concentração de lipídeos totais e perfil de ácidos graxos dos tecidos hepático, muscular, ovariano e uterino. Após as coletas e análise macroscópica dos ovários os animaís de Myliobatiformes, mostrando aparente armazenamento de lipídeos no tecido uterino durante a maturação dos animais, culminando nos maiores valores amostrados no período maduro. Os tecidos uterino e hepático apresentaram concentrações até 100 vezes superiores de lipídeos na comparação com o tecido muscular e ovariano, corroborando o papel armazenados deste substrato nestes tecidos. O perfil de ácidos graxos mostrou um padrão de mobilização de ácidos graxos dos tecidos hepático e muscular para o tecido uterino, notadamente para ácidos graxos polinsaturados (totais, ômega 3 e ômega 6) importantes no desenvolvimento de embriões e juvenis.

Palavras-chave: Histotrofia lipídica; Arraias dulciaquícolas; Perfil de ácidos graxos; Vitelogênese.

\section{Lipid metabolism of viviparous stingray Potamotrygon falkneri Castex \& Maciel, 1963 during reproduction}

\begin{abstract}
Seasonal changes in body composition have been observed in several species of vertebrates, and these changes appear to be related to the vitellogenesis, as well as other processes associated with maternal-fetal transfer and offspring survival. In the case of stingrays, the metabolic distribution and commitment of energy reserves for reproduction will certainly extend to postvitellogenic periods, since the reproductive success of these species will depend on the development of the trophonema and uterine milk, which will serve as a nutritional base for the embryos until the time of parturition. The objective of this work was to investigate the pattern of storage, mobilization and use of lipid substrates and fatty acids involved with the reproduction embryos until the time of parturition. The objective of this work was to investigate the pattern of storage, mobilization and use of lipid substrates and fatty acids involved with the reproduction
of the species Potamotrygon falkneri in different phases of the reproductive cycle. The animals collected were anesthetized and euthanized, with subsequent extraction and determination of the total lipid concentration and fatty acid profile of the liver, muscle, ovarian and uterine tissues. After collections and macroscopic analysis of the ovaries, the animals were separated into three groups, corresponding to the reproductive stages: Rest, Vitelogenesis and Mature. The results support the hypothesis that the lipid histotrophic strategy of Myliobatiformes, showing apparent lipid storage in the uterine tissue during the maturation of the animals, culminating in the highest values sampled in the mature period. The uterine and hepatic tissues showed concentrations up to 100 times higher than lipids in comparison with muscle and ovarian tissue, corroborating the stored role of this substrate in these tissues. The fatty acid profile showed a pattern of fatty acid mobilization from the liver and muscle tissues to the uterine tissue, notably to polyunsaturated fatty acids (total, omega 3 and omega 6) important in the development of embryos and juveniles.
\end{abstract}

Keywords: Lipid histotrophy; Freshwater stingrays; Fatty acid profile; Vitelogenesis.

Topic: Conservação da Biodiversidade

Reviewed anonymously in the process of blind peer.
Received: 02/08/2020 Approved: 19/09/2020
Lucas Spada (iD)

Universidade de São Paulo, Brasil http://lattes.cnpq.br/1587153214216949

http://orcid.org/0000-0002-3615-6248

lucasspada32@gmail.com

Douglas de Castro Ribeiro (iD)

Universidade Estadual Paulista, Brasil

http://lattes.cnpq.br/2676404387074646

http://orcid.org/0000-0003-1455-0014

dcribeiro.bio@gmail.com

Jumma Miranda Araújo Chagas (i)

Universidade Estadual Paulista, Brasil

http://lattes.cnpq.br/5512470374015040

http://orcid.org/0000-0001-7661-5595

jumma.miranda@gmail.com

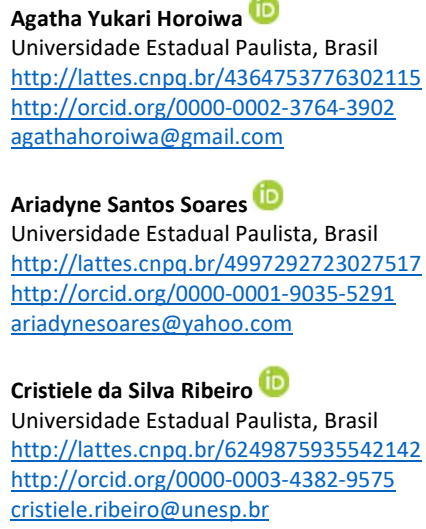

Referencing this:

SPADA, L.; RIBEIRO, D. C.; CHAGAS, J. M. A.; HOROIWA, A. Y.; SOARES, A. S.; RIBEIRO, C. S.. Metabolismo lipídico da raia vivípara Potamotrygon falkneri Castex \& Maciel, 1963 durante a reprodução. Revista Ibero Americana de Ciências Ambientais, v.11, n.5, p.186197, 2020. DOI: http://doi.org/10.6008/CBPC2179$\underline{6858.2020 .005 .0019}$ 


\section{INTRODUÇÃO}

Elasmobrânquios exibem duas estratégias reprodutivas: oviparidade e viviparidade. Arraias da família Potamotrygonidae (Elasmobranchii: Myliobatiformes) apresentam viviparidade aplacentária histotrófica, com embriões retidos no útero das fêmeas até o momento do parto (PEDREROS-SIERRA et al., 2016; SILVA et al., 2017). É possível conjecturar, então, sobre dois períodos de organização metabólica em fêmeas deste grupo, a primeira ligada à vitelogênese ovariana e a segunda ligada ao desenvolvimento de fluido advindo do trofonema uterino, que é rico em lipídeos e proteínas de grande peso molecular, conhecido como "leite uterino", ainda pouco estudado, que servirá de base nutritiva para os embriões até o momento do parto (HAMLETT et al., 1993; MARUSKA et al., 2011; TOBERGTE et al., 2013).

A reprodução dos potamotrigonídeos está relacionada ao ciclo hidrológico, respondendo a uma sequência de eventos, com variação temporal espécie-especifica, sendo a maturação gonadal a primeira de todas as etapas, levando de dois a quatro meses para ser completada; o período de cópula também varia entre as espécies e pode ocorrer durante a estação seca ou chuvosa; a fecundidade ovariana pode variar de um a 11 oócitos por período reprodutivo; a fecundidade uterina de um a oito embriões e a época do nascimento pode durar de três a quatro meses (CHARVET-ALMEIDA et al., 2005; GAMA, 2013; GARRONE NETO et al., 2007). A maior parte da história de vida deste grupo ainda corresponde a dos ancestrais marinhos: baixa taxa de crescimento populacional, maturação lenta, baixa fecundidade e longo período de gestação (CARRIER et al., 2004; CHARVET-ALMEIDA et al., 2005)

Na região do alto rio Paraná, após a inundação do Salto de Sete Quedas para a construção da Usina Hidrelétrica de Itaipu, muitas espécies antes existentes apenas na parte baixa desta Bacia hidrográfica, iniciaram um processo de dispersão, colonizando regiões à jusante desta Bacia, notadamente Potamotrygon falkneri, Potamotrygon motoro e Potamotrygon schuhmacheri, que passaram a desempenhar o papel de espécies invasoras neste novo habitat. Atualmente, as arraias estão estabelecidas até a região de llha Solteira-SP (Alto Paraná), com possibilidade de já terem atingido pontos superiores nesta bacia (LOVEJOY, 1996; CARVALHO, et al., 2003; LASSO et al., 2016).

Visto a importância do entendimento dos processos fisiológicos ligados à dinâmica reprodutiva, adaptações fisiológicas associadas à relação trófica materno-fetal e os padrões de alocação de substratos energéticos durante o ciclo reprodutivo pré e durante a gestação, que possam refletir particularidades nutricionais e ambientais na espécie escolhida, o objetivo deste trabalho foi investigar o padrão de armazenamento, mobilização e utilização de substratos lipídicos e a estrutura de membrana envolvida com a reprodução da espécie $P$. falkneri em diferentes fases do ciclo reprodutivo

\section{MATERIAIS E MÉTODOS}

\section{Coletas}

As coletas de $P$. falkneri (Figura 1b) foram realizadas à montante do reservatório de Porto Primavera,

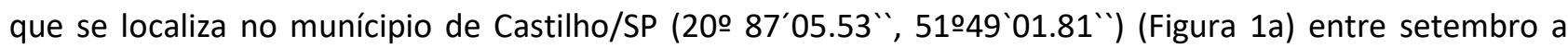


dezembro de 2016. Foram utilizados arpões e varas de mão para a captura (Figura 1c). Os espécimes coletados foram anestesiados com solução saturada de Benzocaína em etanol 92\% na região cardíaca, individualizados em sacos plásticos e armazenados em caixas térmicas de polietileno preenchidas com gelo até o momento da dissecação e transportados vivos para o Laboratório de Estudos em Fisiologia Animal (LEFISA) UNESP/Ilha Solteira onde foram aferidos os dados biométricos (massa, comprimento total (CT), comprimento de disco (CD) e largura de disco (LD)). Os animais coletados apresentaram 4,6 $\pm 3,17 \mathrm{~kg} ; 74,3 \pm$ $6,00 \mathrm{~cm}$ de $\mathrm{CT} ; 47,3 \pm 3,5 \mathrm{~cm}$ de $\mathrm{CD}$ e $44,5 \pm 4,29 \mathrm{~cm}$ de LD.

Os animais coletados foram eutanasiados por secção da medula espinhal e, em seguida foram coletados os seguintes tecidos: musculatura epaxial branca, fígado, ovários e úteros. O cuidado e o uso de animais experimentais obedeceram às leis, diretrizes e políticas do Comitê de Conduta Ética em Uso de Animais (CEUA, 15/2018), conforme aprovado pela Universidade Estadual Paulista, UNESP, e Conselho Nacional de Controle de Experimentação Animal, CONCEA. A permissão para coleta foi fornecida pelo IBAMA/ICMBio (número de autorização do SISBIO 50019-1) e pelo SISGEN (número de registro A001CBE).

Após as coletas e análise macroscópica dos ovários os animais coletados foram separados em três grupos, correspondentes aos estágios reprodutivos: os quais, Repouso $(n=7)$, Vitelogênese $(n=8)$ e Maduro $(n=7)$ (Figura 1 e-g). A classificação dos animais nos estágios reprodutivos foi realizada a partir de análises macroscópicas dos ovários: animais em repouso não apresentaram folículos ovulatórios (Figura 1e), animais em vitelogênese apresentam pequena quantidade de folículos de tamanho reduzido (Figura 1f) e os animais maduros apresentaram grande quantidade de ovócitos e de tamanho grande (Figura 1g).

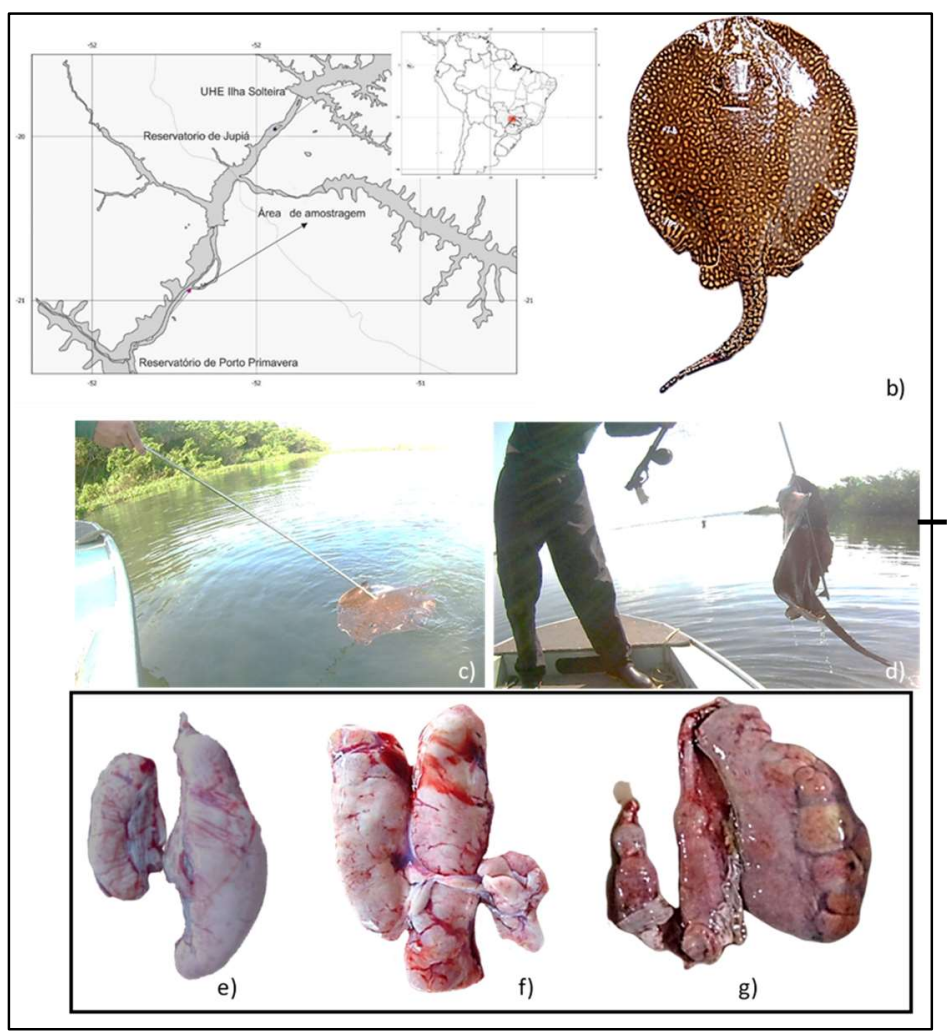

Figura 1: (a) Localização geográfica do local de coleta dos exemplares, Castilho, SP, Brasil, (b) Fêmea adulta de Potamotrygon falkneri, escala de $1 \mathrm{~cm}$, (c-d) Método de captura usando arpão, (e, f, g) Ovários de Potamotrygon falkneri em diferentes estágios do ciclo reprodutivo, e- repouso, f-vitelogênese, g- maduro. 


\section{Análise de tecidos}

A concentração de lipídeos totais dos tecidos (muscular, hepático, ovariano e uterino) foi analisada pelo método colorimétrico de Frings et al. (1972), após extração com uma solução de clorofórmio: metanol: água (FOLCH et al., 1957) adaptada por Parrish (1998), para organismos aquáticos. A concentração de lipídeos totais foi calculada utilizando-se como padrão óleo de fígado de bacalhau (Cod liver oil fatty acid methyl esters, SIGMA) e os resultados expressos em $\mathrm{mg} / \mathrm{g}$ de tecido úmido. O extrato, contendo as diferentes classes de lipídeos, foi separado em lipídeos polares e neutros por cromatografia de coluna (YANG, 1995) e a metilação dos extratos de lipídeos polares e neutros foram realizadas pelo método de Kitson et al. (1996). O perfil dos ácidos graxos foi realizado por cromatografia gasosa, utilizando um cromatográfo gasoso acoplado a um ionizador de chama (FID) (Varian GC 3900) e a identificação dessas moléculas foi feita com base nos tempos de retenção, utilizando-se um padrão composto de metil ésteres (FAME) (SUPELCO, 37 components).

Todos os resultados são apresentados como Média \pm Erro padrão da média. Os valores de cada parâmetro avaliado foram comparados usando o teste de análise de variância (ANOVA), utilizando o programa estatístico Sigma Stat for Windows (Version 3.10 Copyright(C). Os dados que cumpriram os requerimentos de uma análise paramétrica foram comparados pelo teste de Student Newman Keuls e os dados que não cumpriram esses requerimentos foram analisados pelo teste de Dunn's. O nível de significância adotado foi de 0,05.

\section{RESULTADOS}

\section{Lipídeos totais}

Os resultados da análise de lipídeos totais teciduais de fêmeas de $P$. falkneri estão apresentados na figura 2 ( $A, B, C$ e D respectivamente). Foi detectada diferença estatística apenas nos lipídeos uterinos entre o estágio de repouso e maduro, com maiores concentrações no estágio maduro ( $p=0,024)$. Além disso, mesmo sem diferença estatística significativa, pode-se observar que houve um aumento da concentração de lipídeos no músculo e nos ovários analisados quando as fêmeas estavam em vitelogênese e uma posterior queda dessa concentração quando as fêmeas estavam maduras, exceto no tecido hepático, em que a concentração de lipídeos se manteve estável durante todo o ciclo.

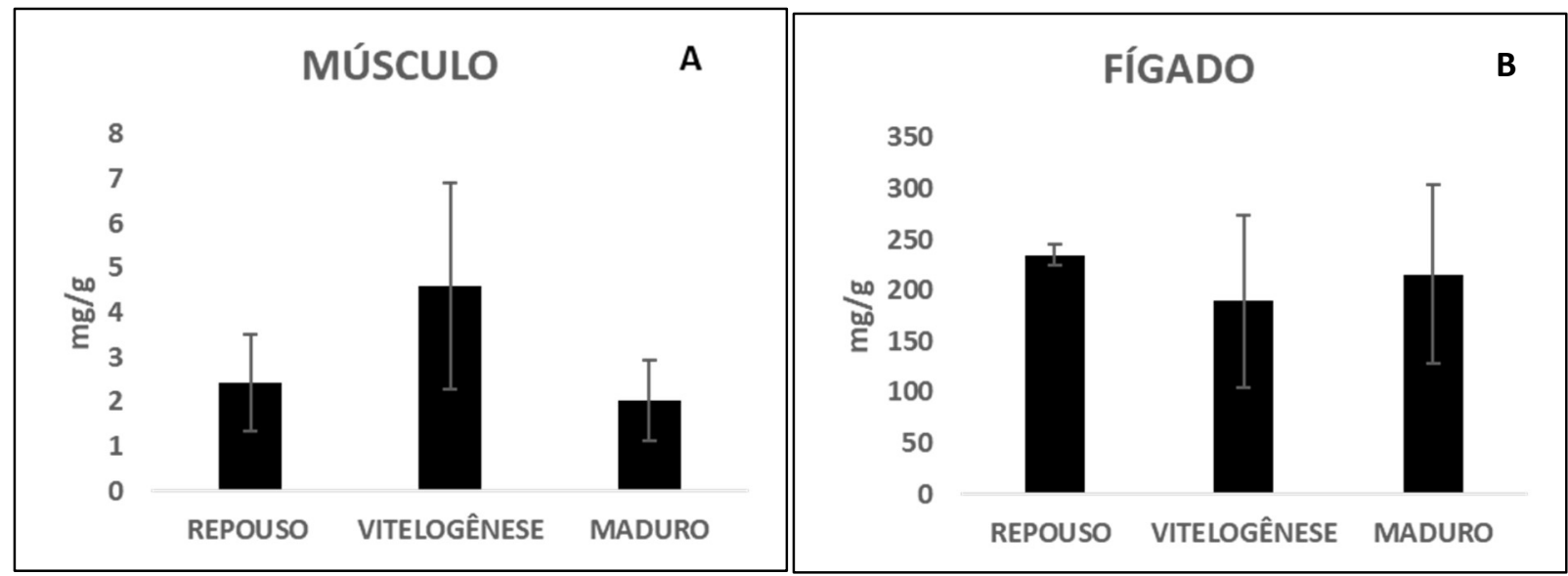




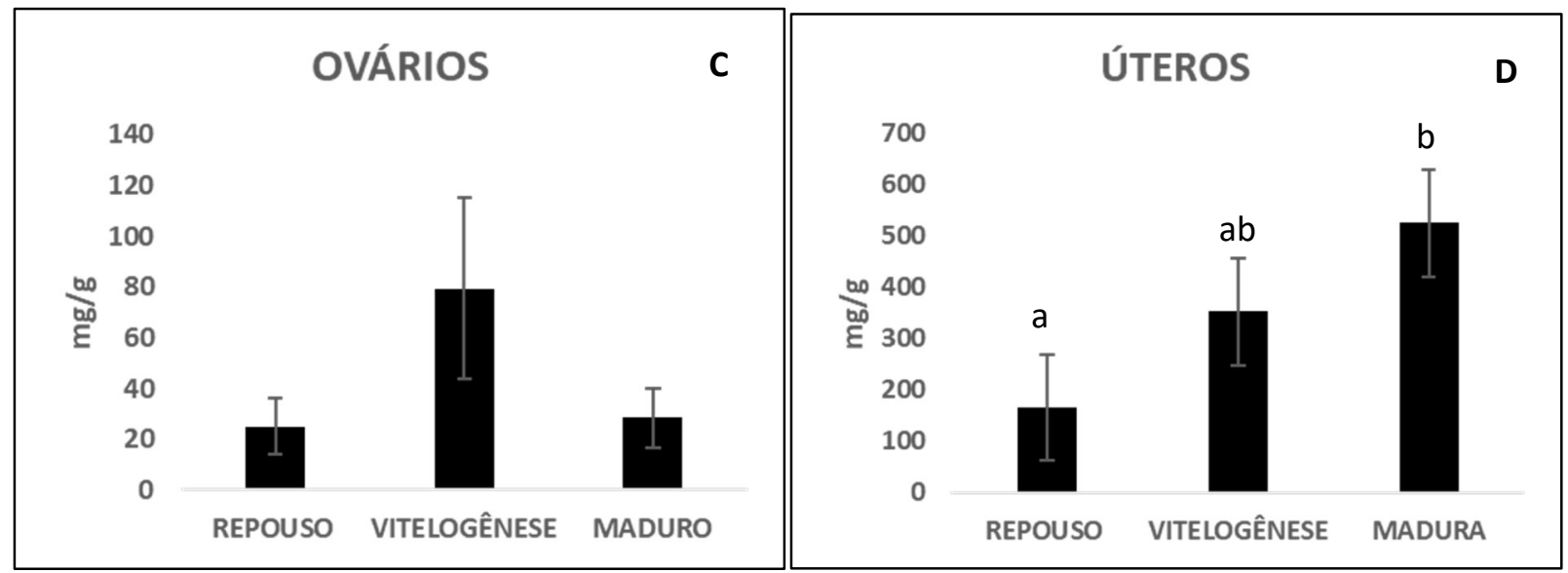

Figura 2: Lipídeos totais em fêmeas de Potamotrygon falkneri em diferentes fases do ciclo reprodutivo, (A) lipídeos musculares, (B) lipídeos hepáticos, (C) lipídeos ovarianos, (D) lipídeos uterinos. ${ }^{\text {a,b ab }}$ Letras diferentes denotam diferenças estatísticas $(p<0,05)$ entre os estágios analisados.

\section{Ácidos graxos}

A determinação do perfil de ácidos graxos dos tecidos dos animais permitiu avaliar a porcentagem de cada ácido graxo e consequentemente os principais agrupamentos, como os ácidos graxos saturados (SAT), monoinsaturados (MUFA) e polinsaturados (PUFA), neste grupo os ácidos graxos da família ômega 3 (PUFAn3) e ômega 6 (PUFAn6) dos quatro tecidos analisados, músculo, fígado, ovários e úteros. Os resultados de cada tecido analisados estão listados nas tabelas 1 a 4.

Tabela 1: Perfil de ácidos graxos (\%) das frações polares e neutras do tecido hepático de fêmeas de Potamotrygon falkneri ao longo do ciclo reprodutivo (Média \pm EPM).

\begin{tabular}{|c|c|c|c|c|c|c|c|c|c|c|c|c|}
\hline \multirow{3}{*}{$\begin{array}{l}\text { Ácido Graxo/ Estágio } \\
\text { C15:0 }\end{array}$} & \multicolumn{6}{|c|}{ Fração Polar } & \multicolumn{6}{|c|}{ Fração Neutra } \\
\hline & \multicolumn{2}{|c|}{ REPOUSO } & \multicolumn{2}{|c|}{ VITELOGÊNESE } & \multicolumn{2}{|c|}{ MADURO } & \multicolumn{2}{|c|}{ REPOUSO } & \multicolumn{2}{|c|}{ VITELOGÊNESE } & \multicolumn{2}{|c|}{ MADURO } \\
\hline & 1,15 & $\pm 0,55$ & 0,90 & $\pm 0,76$ & 1,08 & $\pm 1,38$ & 0,45 & $\pm 0,20$ & 0,38 & $\pm 0,04$ & 0,28 & $\pm 0,08$ \\
\hline C16:0 & 23,65 & $\pm 2,13$ & 20,26 & $\pm 5,86$ & 22,02 & $\pm 1,26$ & 26,07 & $\pm 0,92$ & 25,28 & $\pm 1,47$ & 21,66 & $\pm 0,92$ \\
\hline C16:1 & 4,43 & $\pm 0,61$ & 2,40 & $\pm 0,07$ & 3,30 & $\pm 1,03$ & 4,33 & $\pm 0,22$ & 4,94 & $\pm 1,67$ & 3,64 & $\pm 0,12$ \\
\hline C18:0 & 12,50 & $\pm 1,11$ & 12,80 & $\pm 4,65$ & 9,29 & $\pm 2,95$ & 8,64 & $\pm 0,83$ & 6,78 & $\pm 0,62$ & 5,95 & $\pm 0,13$ \\
\hline C18:1 & 20,98 & $\pm 4,33$ & 23,10 & $\pm 6,29$ & 32,81 & $\pm 3,11$ & 28,43 & $\pm 3,52$ & 36,09 & $\pm 2,78$ & 35,64 & $\pm 1,46$ \\
\hline $\mathrm{C} 18: 2 \mathrm{n} 6$ & 4,69 & $\pm 0,48$ & 4,30 & $\pm 1,24$ & 5,36 & $\pm 0,71$ & 6,25 & $\pm 0,38$ & 5,30 & $\pm 0,42$ & 5,87 & $\pm 0,26$ \\
\hline C18:3n3 & 1,73 & $\pm 0,65$ & 1,56 & $\pm 0,53$ & 1,19 & $\pm 0,10$ & 1,68 & $\pm 0,56$ & 1,62 & $\pm 0,24$ & 1,25 & $\pm 0,11$ \\
\hline C20:0 & 0,20 & $\pm 0,07$ & 1,33 & $\pm 2,88$ & 0,26 & $\pm 0,10$ & 1,88 & $\pm 0,64$ & 1,58 & $\pm 0,40$ & 3,21 & $\pm 0,82$ \\
\hline$C 20: 1$ & 2,16 & $\pm 0,49$ & 0,60 & $\pm 0,08$ & 1,08 & $\pm 0,33$ & 0,39 & $\pm 0,56$ & 0,27 & $\pm 0,10$ & 0,50 & $\pm 0,20$ \\
\hline C20:2n6 & 1,55 & $\pm 0,22$ & 2,73 & $\pm 0,57$ & 1,54 & $\pm 0,38$ & 0,99 & $\pm 0,24$ & 0,75 & $\pm 0,23$ & 0,66 & $\pm 0,54$ \\
\hline C21:0 & 0,49 & $\pm 0,22$ & 0,76 & $\pm 0,29$ & 0,27 & $\pm 0,14$ & 0,83 & $\pm 0,04$ & 0,45 & $\pm 0,10$ & 0,64 & $\pm 0,19$ \\
\hline C20:4n6 & 0,78 & $\pm 0,96$ & 1,09 & $\pm 5,30$ & 0,92 & $\pm 0,24$ & 4,71 & $\pm 1,55$ & 5,18 & $\pm 1,07$ & 3,47 & $\pm 1,54$ \\
\hline$C 20: 3 n 3$ & 0,76 & $\pm 0,17$ & 0,46 & $\pm 0,12$ & 0,86 & $\pm 0,21$ & 0,09 & $\pm 0,17$ & 0,21 & $\pm 0,05$ & 0,15 & $\pm 0,04$ \\
\hline$C 20: 5 n 3$ & 9,11 & $\pm 1,13$ & 7,62 & $\pm 3,62$ & 7,08 & $\pm 0,78$ & 4,43 & $\pm 1,93$ & 1,98 & $\pm 0,88$ & 4,07 & $\pm 1,09$ \\
\hline$C 22: 0$ & 0,20 & $\pm 0,09$ & 0,25 & $\pm 0,32$ & 0,04 & $\pm 0,05$ & 0,07 & $\pm 0,03$ & 0,13 & $\pm 0,07$ & 0,04 & $\pm 0,40$ \\
\hline C22:1 & 0,21 & $\pm 0,06$ & 0,47 & $\pm 0,15$ & 0,19 & $\pm 0,06$ & 0,20 & $\pm 0,03$ & 0,20 & $\pm 0,06$ & 0,10 & $\pm 0,07$ \\
\hline $\mathrm{C} 22: 4 \mathrm{n} 3$ & 6,44 & $\pm 2,32$ & 1,73 & $\pm 0,72$ & 1,98 & $\pm 0,39$ & 0,34 & $\pm 1,29$ & 0,31 & $\pm 0,30$ & 0,49 & $\pm 0,40$ \\
\hline$C 22: 5 n 6$ & 1,95 & $\pm 0,70$ & 1,46 & $\pm 0,18$ & 1,86 & $\pm 0,30$ & 1,90 & $\pm 0,42$ & 2,06 & $\pm 0,35$ & 3,30 & $\pm 0,62$ \\
\hline $\mathrm{C} 22: 6 \mathrm{n} 3$ & 5,89 & $\pm 0,31$ & 2,44 & $\pm 1,11$ & 6,74 & $\pm 0,95$ & 5,79 & $\pm 0,54$ & 6,29 & $\pm 0,37$ & 8,17 & $\pm 0,21$ \\
\hline $\mathrm{C} 24: 0$ & 0,04 & $\pm 0,06$ & 1,86 & $\pm 0,69$ & 0,11 & $\pm 0,04$ & 0,02 & $\pm 0,01$ & 0,02 & $\pm 0,01$ & 0,03 & $\pm 0,00$ \\
\hline SAT & 38,07 & $\pm 0,53$ & 33,75 & $\pm 5,19$ & 34,44 & $\pm 3,14$ & 38,19 & $\pm 0,58^{a}$ & 34,46 & $\pm 1,82^{\mathrm{ab}}$ & 31,91 & $\pm 0,87^{b}$ \\
\hline MUFA & 29,00 & $\pm 3,47^{b}$ & 27,03 & $\pm 6,16^{\mathrm{ab}}$ & 36,66 & $\pm 3,06^{a}$ & 33,48 & $\pm 2,95$ & 41,42 & $\pm 1,23$ & 39,77 & $\pm 1,61$ \\
\hline PUFA & 32,93 & $\pm 3,95^{a}$ & 31,04 & $\pm 4,01^{\mathrm{ab}}$ & 28,44 & $\pm 2,06^{a}$ & 28,49 & $\pm 3,07$ & 23,70 & $\pm 1,14$ & 28,32 & $\pm 0,84$ \\
\hline PUFA n3 & 26,60 & $\pm 3,85^{a}$ & 14,90 & $\pm 3,08^{b}$ & 17,61 & $\pm 1,93^{b}$ & 12,94 & $\pm 3,47$ & 10,82 & $\pm 1,37$ & 14,00 & $\pm 1,41$ \\
\hline PUFA n6 & 10,31 & $\pm 1,62$ & 10,64 & $\pm 5,54$ & 9,46 & $\pm 0,91$ & 13,92 & $\pm 2,02$ & 13,28 & $\pm 1,81$ & 13,17 & $\pm 1,93$ \\
\hline
\end{tabular}

${ }^{a b}$ Letras diferentes denotam diferenças estatísticas $(P<0,05)$ ao longo do ciclo anual para fêmeas. Valores abaixo de 0.1 não foram considerados. SAT, MUFA, PUFA, PUFAn6, E PUFAn3, são as somatórias dos ácidos graxos saturados, monoinsaturados, polinsaturados n6, e polinsaturados n3. 
Tabela 2: Perfil de ácidos graxos (\%) das frações polares e neutras do tecido muscular de fêmeas de Potamotrygon falkneri ao longo do ciclo reprodutivo (Média \pm EPM).

\begin{tabular}{|c|c|c|c|c|c|c|c|c|c|c|c|c|}
\hline \multirow{3}{*}{$\begin{array}{l}\text { Ácido Graxo/ Estágio } \\
\text { C16:0 }\end{array}$} & \multicolumn{6}{|c|}{ Fração Polar } & \multicolumn{6}{|c|}{ Fração Neutra } \\
\hline & \multicolumn{2}{|c|}{ REPOUSO } & \multicolumn{2}{|c|}{ VITELOGÊNESE } & \multicolumn{2}{|c|}{ MADURO } & \multicolumn{2}{|c|}{ REPOUSO } & \multicolumn{2}{|c|}{ VITELOGÊNESE } & \multicolumn{2}{|c|}{ MADURO } \\
\hline & 15,52 & $\pm 2,98$ & 16,05 & $\pm 1,75$ & 16,26 & $\pm 2,70$ & 20,59 & $\pm 1,56$ & 15,47 & $\pm 2,73$ & 19,46 & $\pm 1,42$ \\
\hline C16:1 & 9,05 & $\pm 2,03$ & 6,31 & $\pm 2,24$ & 8,48 & $\pm 1,22$ & 13,38 & $\pm 4,66$ & 29,86 & $\pm 10,19$ & 21,58 & $\pm 2,72$ \\
\hline C18:0 & 21,48 & $\pm 3,89$ & 15,65 & $\pm 2,28$ & 25,08 & $\pm 5,15$ & 14,37 & $\pm 1,37$ & 14,13 & $\pm 1,41$ & 11,94 & $\pm 1,73$ \\
\hline C18:1 & 11,40 & $\pm 2,54$ & 18,04 & $\pm 4,14$ & 17,94 & $\pm 6,41$ & 16,32 & $\pm 2,17$ & 12,01 & $\pm 7,70$ & 19,97 & $\pm 1,93$ \\
\hline C18:2n6 & 1,97 & $\pm 0,43$ & 4,83 & $\pm 0,97$ & 2,91 & $\pm 1,04$ & 3,12 & $\pm 0,90$ & 2,16 & $\pm 1,58$ & 2,11 & $\pm 1,37$ \\
\hline C18:3n6 & 1,06 & $\pm 0,28$ & 1,11 & $\pm 0,08$ & 0,85 & $\pm 0,43$ & 1,03 & $\pm 0,34$ & 0,99 & $\pm 1,16$ & 0,10 & $\pm 1,31$ \\
\hline C18:3n3 & 1,31 & $\pm 0,29$ & 1,66 & $\pm 0,38$ & 0,78 & $\pm 0,30$ & 2,30 & $\pm 0,55$ & 3,59 & $\pm 2,35$ & 1,59 & $\pm 0,74$ \\
\hline C20:0 & 2,04 & $\pm 0,66$ & 3,63 & $\pm 0,85$ & 0,74 & $\pm 0,26$ & 2,55 & $\pm 0,63$ & 2,68 & $\pm 0,25$ & 2,78 & $\pm 1,77$ \\
\hline C20:1 & 0,59 & $\pm 0,19$ & 0,31 & $\pm 0,30$ & 0,78 & $\pm 0,08$ & 0,64 & $\pm 0,42$ & 0,27 & $\pm 0,20$ & 0,47 & $\pm 0,76$ \\
\hline$C 20: 4 n 6$ & 13,49 & $\pm 2,03$ & 12,38 & $\pm 3,04$ & 11,57 & $\pm 2,15$ & 6,91 & $\pm 2,76$ & 5,51 & $\pm 1,79$ & 1,43 & $\pm 1,10$ \\
\hline$C 20: 3 n 3$ & 0,58 & $\pm 0,44$ & 1,45 & $\pm 0,20$ & 0,23 & $\pm 0,08$ & 0,74 & $\pm 0,28$ & 1,13 & $\pm 1,15$ & 1,86 & $\pm 1,48$ \\
\hline C20:5n3 & 1,94 & $\pm 1,22$ & 1,88 & $\pm 0,30$ & 1,47 & $\pm 0,50$ & 3,62 & $\pm 0,45$ & 5,34 & $\pm 2,37$ & 5,56 & $\pm 1,39$ \\
\hline$C 22: 5 n 3$ & 2,14 & $\pm 0,38$ & 1,53 & $\pm 0,54$ & 1,16 & $\pm 0,38$ & 1,64 & $\pm 0,36$ & 1,12 & $\pm 0,55$ & 1,26 & $\pm 1,65$ \\
\hline C22:5n6 & 4,08 & $\pm 0,88$ & 2,09 & $\pm 0,36$ & 1,92 & $\pm 0,25$ & 2,33 & $\pm 0,41$ & 2,40 & $\pm 0,87$ & 2,31 & $\pm 0,64$ \\
\hline C22:6n3 & 9,83 & $\pm 1,46$ & 7,51 & $\pm 1,07$ & 7,32 & $\pm 0,96$ & 4,59 & $\pm 1,77$ & 2,75 & $\pm 1,66$ & 3,76 & $\pm 1,19$ \\
\hline C24:0 & 0,83 & $\pm 0,24$ & 0,49 & $\pm 0,22$ & 0,08 & $\pm 0,03$ & 0,79 & $\pm 0,24$ & 0,33 & $\pm 0,14$ & 0,81 & $\pm 0,24$ \\
\hline SAT & 43,69 & $\pm 3,70$ & 37,32 & $\pm 1,93$ & 42,16 & $\pm 2,77$ & 37,80 & $\pm 1,53$ & 32,25 & $\pm 1,76$ & 34,99 & $\pm 2,42$ \\
\hline MUFA & 20,48 & $\pm 1,15$ & 27,42 & $\pm 4,64$ & 27,20 & $\pm 5,34$ & 33,01 & $\pm 3,71$ & 41,43 & $\pm 2,47$ & 38,89 & $\pm 2,97$ \\
\hline PUFA & 36,32 & $\pm 3,58$ & 33,91 & $\pm 5,24$ & 29,49 & $\pm 2,81$ & 24,68 & $\pm 4,65$ & 30,19 & $\pm 1,71$ & 26,13 & $\pm 5,01$ \\
\hline PUFA n3 & 16,74 & $\pm 1,33^{a}$ & 14,28 & $\pm 1,89^{a b}$ & 11,87 & $\pm 1,41^{b}$ & 14,45 & $\pm 1,48$ & 13,67 & $\pm 4,06$ & 14,24 & $\pm 4,89$ \\
\hline PUFA n6 & 19,30 & $\pm 2,45$ & 19,64 & $\pm 3,46$ & 17,62 & $\pm 1,40$ & 13,83 & $\pm 3,40$ & 12,13 & $\pm 3,80$ & 7,29 & $\pm 2,41$ \\
\hline
\end{tabular}

${ }^{\mathrm{ab}}$ Letras diferentes denotam diferenças estatísticas $(\mathrm{P}<0,05)$ ao longo do ciclo anual para fêmeas. Valores abaixo de 0.1 não foram considerados. SAT, MUFA, PUFA, PUFAn6, E PUFAn3, são as somatórias dos ácidos graxos saturados, monoinsaturados, polinsaturados $n 6$, e polinsaturados $n 3$.

Adicionalmente foram divididas as frações neutras e polares teciduais, com vistas a determinar o perfil energético e estrutural dos lipídeos. Fazendo-se uma análise da variedade de ácidos graxos da fração neutra foi possível observar alta prevalência de C16:0 e C18:0 como SAT com maior representatividade, C16:1 e C18:1, C20:1, C14:1, C15:1 e C20:1n9 como MUFA prevalentes e C18:2n6, C20:5n3 e C22:6n3, C16:3n4, C20:4n6, C16:2n4 e C22:5n3 como principais PUFA. Para os ácidos graxos da fração polar observou-se alta prevalência de C15:0, C16:0 e C18:0 como principais SAT, C14:1, C18:1 e C20:1 como principais MUFA, C16:2n4, C16:3n4, C18:2n6, C20:4n6, e C22:6n3 para PUFA.

Para a fração neutra do tecido hepático (Tabela 1) foi possível detectar que o período de vitelogênese não apresentou diferenças quando comparado com os períodos de repouso e maduro, demostrando uma inatividade metabólica neste momento da reprodução no tecido hepático. Por outro lado, entre o período de repouso e maduro foi possível detectar maiores valores para SAT em animais em repouso, na comparação com animais maduros $(p=0,048)$. 0 mesmo padrão foi detectado para o tecido uterino (Tabela 4), maiores valores de SAT para o período de repouso na comparação com maduro $(p=0,035)$. Os tecidos musculares (Tabela2) e ovariano (Tabela 3) não apresentaram influência do estágio reprodutivo nos ácidos graxos na fração neutra, fato que pode ser explicado pelos altos valores de desvio padrão encontrados, demostrando alta variabilidade individual.

Tabela 3: Perfil de ácidos graxos (\%) das frações polares e neutras do tecido ovariano fêmeas de Potamotrygon falkneri ao longo do ciclo reprodutivo (Média \pm EPM).

\begin{tabular}{|c|c|c|c|c|c|c|}
\hline & Fração Polar & & & Fração Neutra & & \\
\hline Ácido Graxo/ Estágio & REPOUSO & VITELOGÊNESE & MADURO & REPOUSO & VITELOGÊNESE & MADURO \\
\hline C15:0 & $16,00 \pm 4,11$ & $17,40 \pm 5,00$ & $18,51 \pm 3,47$ & $21,76 \pm 1,43$ & $\pm 4,73$ & $16,86 \pm 2,33$ \\
\hline C16:0 & $11,22 \pm 1,04$ & $11,24 \pm 1,16$ & $12,33 \pm 0,39$ & $10,17 \pm 1,26$ & $\pm 2,08$ & $13,91 \pm 3,07$ \\
\hline
\end{tabular}




\begin{tabular}{|c|c|c|c|c|c|c|c|c|c|c|c|c|}
\hline C16:1 & 12,22 & $\pm 1,96$ & 14,23 & $\pm 3,51$ & 14,76 & $\pm 2,95$ & 15,70 & $\pm 0,83$ & 11,30 & $\pm 2,66$ & 12,42 & $\pm 1,09$ \\
\hline C18:0 & 14,01 & $\pm 1,71$ & 16,16 & $\pm 1,73$ & 14,09 & $\pm 2,28$ & 8,56 & $\pm 0,93$ & 10,84 & $\pm 0,96$ & 8,00 & $\pm 0,39$ \\
\hline C18:1 & 18,83 & $\pm 1,34$ & 16,91 & $\pm 0,91$ & 17,53 & $\pm 1,53$ & 15,85 & $\pm 1,23$ & 25,79 & $\pm 2,69$ & 19,50 & $\pm 3,63$ \\
\hline C18:2n6 & 0,29 & $\pm 0,05$ & 0,37 & $\pm 0,33$ & 0,34 & $\pm 0,05$ & 0,04 & $\pm 0,06$ & 0,20 & $\pm 0,11$ & 0,31 & $\pm 0,12$ \\
\hline C18:3n6 & 0,92 & $\pm 0,40$ & 1,17 & $\pm 0,90$ & 1,00 & $\pm 0,26$ & 2,03 & $\pm 0,42$ & 3,15 & $\pm 1,04$ & 2,03 & $\pm 0,56$ \\
\hline C18:3n3 & 1,65 & $\pm 0,39$ & 1,73 & $\pm 2,02$ & 1,73 & $\pm 0,33$ & 3,37 & $\pm 0,35$ & 1,56 & $\pm 0,27$ & 2,54 & $\pm 0,16$ \\
\hline C20:0 & 0,51 & $\pm 0,18$ & 0,52 & $\pm 1,31$ & 0,18 & $\pm 0,06$ & 0,34 & $\pm 0,63$ & 0,34 & $\pm 0,11$ & 0,06 & $\pm 0,02$ \\
\hline C20:1 & 2,81 & $\pm 0,41$ & 3,35 & $\pm 1,58$ & 3,16 & $\pm 0,65$ & 3,94 & $\pm 0,43$ & 2,31 & $\pm 0,87$ & 3,09 & $\pm 0,71$ \\
\hline$C 20: 2 n 6$ & 1,23 & $\pm 0,50$ & 1,38 & $\pm 0,45$ & 1,92 & $\pm 0,54$ & 3,09 & $\pm 0,33$ & 1,24 & $\pm 0,35$ & 0,93 & $\pm 1,09$ \\
\hline C21:0 & 0,31 & $\pm 0,11$ & 0,48 & $\pm 0,62$ & 0,18 & $\pm 0,14$ & 0,32 & $\pm 0,19$ & 0,35 & $\pm 0,15$ & 0,54 & $\pm 0,24$ \\
\hline C20:4n6 & 7,34 & $\pm 2,41$ & 4,54 & $\pm 4,09$ & 3,83 & $\pm 1,09$ & 2,48 & $\pm 0,16$ & 2,01 & $\pm 2,11$ & 2,62 & $\pm 0,40$ \\
\hline C20:4n3 & 0,43 & $\pm 0,12$ & 0,97 & $\pm 0,20$ & 0,95 & $\pm 0,37$ & 1,34 & $\pm 0,52$ & 0,74 & $\pm 0,37$ & 0,71 & $\pm 1,11$ \\
\hline$C 20: 5 n 3$ & 0,59 & $\pm 0,50$ & 0,31 & $\pm 0,78$ & 0,32 & $\pm 0,05$ & 0,19 & $\pm 0,13$ & 0,71 & $\pm 0,12$ & 0,63 & $\pm 0,15$ \\
\hline C21:5n3 & 1,63 & $\pm 0,28$ & 1,32 & $\pm 0,33$ & 1,38 & $\pm 0,20$ & 2,24 & $\pm 0,10$ & 0,91 & $\pm 0,43$ & 1,50 & $\pm 0,13$ \\
\hline C22:1 & 0,49 & $\pm 0,14$ & 0,99 & $\pm 0,44$ & 0,75 & $\pm 0,36$ & 0,76 & $\pm 0,55$ & 0,52 & $\pm 0,30$ & 0,47 & $\pm 1,15$ \\
\hline$C 22: 4 n 6$ & 1,74 & $\pm 1,23$ & 1,53 & $\pm 0,68$ & 1,74 & $\pm 0,72$ & 0,91 & $\pm 0,61$ & 1,13 & $\pm 0,76$ & 0,32 & $\pm 0,31$ \\
\hline$C 22: 5 n 3$ & 0,47 & $\pm 0,24$ & 0,41 & $\pm 0,47$ & 0,37 & $\pm 1,12$ & 0,71 & $\pm 0,10$ & 1,83 & $\pm 0,39$ & 0,58 & $\pm 0,16$ \\
\hline$C 22: 6 n 3$ & 2,01 & $\pm 0,46$ & 1,46 & $\pm 0,63$ & 1,17 & $\pm 9,68$ & 1,60 & $\pm 0,28$ & 1,87 & $\pm 1,31$ & 3,07 & $\pm 0,23$ \\
\hline C24:0 & 0,06 & $\pm 0,04$ & 0,18 & $\pm 0,28$ & 0,17 & $\pm 0,25$ & 0,11 & $\pm 0,03$ & 0,05 & $\pm 0,08$ & 0,07 & $\pm 0,03$ \\
\hline SAT & 43,99 & $\pm 2,44$ & 44,97 & $\pm 3,24$ & 47,02 & $\pm 5,72$ & 43,34 & $\pm 0,86$ & 41,63 & $\pm 3,16$ & 44,60 & $\pm 1,90$ \\
\hline MUFA & 35,39 & $\pm 1,21$ & 35,53 & $\pm 2,99$ & 36,28 & $\pm 5,39$ & 37,14 & $\pm 1,45$ & 38,97 & $\pm 1,68$ & 39,81 & $\pm 2,05$ \\
\hline PUFA & 20,83 & $\pm 3,43$ & 18,53 & $\pm 6,07$ & 16,70 & $\pm 10,42$ & 17,81 & $\pm 1,31$ & 17,15 & $\pm 4,40$ & 15,58 & $\pm 3,78$ \\
\hline PUFA n3 & 7,08 & $\pm 0,79$ & 6,65 & $\pm 2,49$ & 6,73 & $\pm 10,05$ & 9,72 & $\pm 0,96$ & 8,33 & $\pm 1,01$ & 9,56 & $\pm 1,62$ \\
\hline PUFA n6 & 12,66 & $\pm 3,34^{b}$ & 8,78 & $\pm 5,43^{a}$ & 9,08 & $\pm 1,48 \mathrm{ab}$ & 9,02 & $\pm 0,66$ & 8,82 & $\pm 3,50$ & 6,03 & $\pm 2,17$ \\
\hline
\end{tabular}

${ }^{\mathrm{ab}}$ Letras diferentes denotam diferenças estatísticas $(\mathrm{P}<0,05)$ ao longo do ciclo anual para fêmeas. Valores abaixo de 0.1 não foram considerados. SAT, MUFA, PUFA, PUFAn6, E PUFAn3, são as somatórias dos ácidos graxos saturados, monoinsaturados, polinsaturados $n 6$, e polinsaturados $n 3$.

Tabela 4: Perfil de ácidos graxos (\%) das frações polares e neutras do tecido uterino de fêmeas de Potamotrygon falkneri ao longo do ciclo reprodutivo (Média \pm EPM).

\begin{tabular}{|c|c|c|c|c|c|c|c|c|c|c|c|c|}
\hline \multirow{3}{*}{$\begin{array}{l}\text { Ácido Graxo/ Estágio } \\
\text { C15:0 }\end{array}$} & \multicolumn{6}{|c|}{ Fração Polar } & \multicolumn{6}{|c|}{ Fração Neutra } \\
\hline & \multicolumn{2}{|c|}{ REPOUSO } & \multicolumn{2}{|c|}{ VITELOGÊNESE } & \multicolumn{2}{|c|}{ MADURO } & \multicolumn{2}{|c|}{ REPOUSO } & \multicolumn{2}{|c|}{ VITELOGÊNESE } & \multicolumn{2}{|c|}{ MADURO } \\
\hline & 7,00 & $\pm 2,41$ & 7,34 & $\pm 3,18$ & 7,53 & $\pm 2,42$ & 5,29 & $\pm 3,04$ & 7,16 & $\pm 4,01$ & 3,40 & $\pm 4,01$ \\
\hline C15:1 & 9,96 & $\pm 2,13$ & 17,12 & $\pm 0,91$ & 10,57 & $\pm 1,03$ & 13,09 & $\pm 1,67$ & 10,89 & $\pm 4,08$ & 12,57 & $\pm 3,56$ \\
\hline C16:0 & 7,02 & $\pm 2,44$ & 6,14 & $\pm 2,31$ & 1,65 & $\pm 1,81$ & 4,77 & $\pm 2,13$ & 5,02 & $\pm 3,03$ & 3,75 & $\pm 0,94$ \\
\hline C16:1 & 14,80 & $\pm 2,13$ & 10,82 & $\pm 1,52$ & 17,55 & $\pm 1,34$ & 6,78 & $\pm 2,70$ & 11,53 & $\pm 5,68$ & 11,12 & $\pm 6,29$ \\
\hline C18:0 & 12,21 & $\pm 2,23$ & 23,83 & $\pm 3,67$ & 13,55 & $\pm 0,86$ & 13,46 & $\pm 3,49$ & 13,43 & $\pm 5,68$ & 17,17 & $\pm 3,34$ \\
\hline C18:1 & 3,18 & $\pm 4,82$ & 3,87 & $\pm 0,74$ & 2,82 & $\pm 0,08$ & 2,10 & $\pm 0,64$ & 1,62 & $\pm 1,10$ & 1,85 & $\pm 0,92$ \\
\hline $\mathrm{C} 18: 2 \mathrm{n} 6$ & 0,64 & $\pm 0,79$ & 0,12 & $\pm 0,11$ & 0,66 & $\pm 0,21$ & 7,70 & $\pm 4,38$ & 3,01 & $\pm 2,14$ & 8,67 & $\pm 4,59$ \\
\hline C18:3n6 & 0,52 & $\pm 0,09$ & 0,68 & $\pm 0,30$ & 0,33 & $\pm 0,37$ & 0,51 & $\pm 0,22$ & 0,39 & $\pm 0,24$ & 0,19 & $\pm 0,06$ \\
\hline C18:3n3 & 0,57 & $\pm 0,16$ & 0,26 & $\pm 0,16$ & 0,33 & $\pm 0,14$ & 1,38 & $\pm 1,52$ & 1,39 & $\pm 1,29$ & 1,03 & $\pm 0,50$ \\
\hline C20:0 & 1,42 & $\pm 0,26$ & 1,12 & $\pm 0,12$ & 2,17 & $\pm 0,90$ & 0,84 & $\pm 0,28$ & 1,12 & $\pm 0,78$ & 1,17 & $\pm 0,33$ \\
\hline C20:1 & 1,91 & $\pm 0,51$ & 0,58 & $\pm 0,95$ & 1,30 & $\pm 0,99$ & 1,51 & $\pm 0,53$ & 1,06 & $\pm 0,40$ & 1,08 & $\pm 0,16$ \\
\hline C20:2n6 & 0,96 & $\pm 0,42$ & 0,36 & $\pm 0,95$ & 1,14 & $\pm 0,35$ & 1,87 & $\pm 4,60$ & 9,79 & $\pm 3,66$ & 7,41 & $\pm 2,69$ \\
\hline$C 20: 4 n 6$ & 18,30 & $\pm 3,14$ & 8,74 & $\pm 2,68$ & 21,38 & $\pm 1,63$ & 6,50 & $\pm 2,32$ & 1,03 & $\pm 1,50$ & 0,97 & $\pm 3,29$ \\
\hline C20:3n6 & 0,25 & $\pm 0,16$ & 1,06 & $\pm 0,48$ & 0,73 & $\pm 0,26$ & 0,53 & $\pm 0,26$ & 0,97 & $\pm 0,81$ & 4,32 & $\pm 2,35$ \\
\hline$C 20: 4 n 3$ & 2,21 & $\pm 0,50$ & 2,28 & $\pm 0,51$ & 2,43 & $\pm 1,05$ & 3,70 & $\pm 1,20$ & 0,27 & $\pm 0,31$ & 1,31 & $\pm 2,38$ \\
\hline C20:5n3 & 0,47 & $\pm 0,29$ & 0,45 & $\pm 0,26$ & 0,43 & $\pm 0,05$ & 0,30 & $\pm 0,10$ & 0,68 & $\pm 0,34$ & 0,30 & $\pm 0,38$ \\
\hline$C 21: 5 n 3$ & 0,96 & $\pm 0,30$ & 0,44 & $\pm 0,19$ & 0,36 & $\pm 0,11$ & 0,10 & $\pm 0,35$ & 3,52 & $\pm 0,96$ & 0,87 & $\pm 0,58$ \\
\hline C22:1 & 0,81 & $\pm 0,87$ & 1,57 & $\pm 0,29$ & 1,41 & $\pm 1,39$ & 1,21 & $\pm 1,22$ & 2,46 & $\pm 0,35$ & 2,76 & $\pm 1,13$ \\
\hline C22:4n6 & 2,83 & $\pm 0,40$ & 2,30 & $\pm 0,28$ & 2,30 & $\pm 0,89$ & 1,26 & $\pm 0,52$ & 1,45 & $\pm 0,88$ & 1,22 & $\pm 0,83$ \\
\hline$C 22: 5 n 6$ & 1,89 & $\pm 0,34$ & 1,50 & $\pm 0,84$ & 1,26 & $\pm 0,90$ & 0,97 & $\pm 0,33$ & 2,33 & $\pm 0,94$ & 2,04 & $\pm 0,66$ \\
\hline$C 22: 5 n 3$ & 2,62 & $\pm 0,22$ & 3,57 & $\pm 2,31$ & 1,69 & $\pm 0,60$ & 0,90 & $\pm 0,11$ & 0,99 & $\pm 0,16$ & 0,47 & $\pm 0,66$ \\
\hline$C 22: 6 n 3$ & 1,87 & $\pm 1,47$ & 2,77 & $\pm 1,77$ & 4,13 & $\pm 3,87$ & 4,14 & $\pm 1,44$ & 6,36 & $\pm 0,80$ & 2,19 & $\pm 2,07$ \\
\hline C24:0 & 0,07 & $\pm 0,02$ & 0,47 & $\pm 0,24$ & 0,51 & $\pm 0,22$ & 0,04 & $\pm 0,16$ & 0,14 & $\pm 0,12$ & 0,59 & $\pm 0,38$ \\
\hline SAT & 41,45 & $\pm 2,75^{b}$ & 57,00 & $\pm 9,50^{a}$ & 37,77 & $\pm 4,22^{b}$ & 50,38 & $\pm 6,13^{\mathrm{a}}$ & 42,36 & $\pm 3,35^{\mathrm{ab}}$ & 38,44 & $\pm 2,55^{a}$ \\
\hline MUFA & 22,64 & $\pm 2,91$ & 16,09 & $\pm 3,11$ & 23,59 & $\pm 0,84$ & 14,36 & $\pm 2,60$ & 17,88 & $\pm 4,87$ & 19,39 & $\pm 6,30$ \\
\hline PUFA & 35,27 & $\pm 2,08^{b}$ & 28,76 & $\pm 6,76^{a}$ & 40,67 & $\pm 4,89^{b}$ & 37,83 & $\pm 7,45$ & 38,36 & $\pm 2,82$ & 39,43 & $\pm 6,09$ \\
\hline PUFA n3 & 10,58 & $\pm 1,22$ & 13,75 & $\pm 2,54$ & 13,44 & $\pm 4,36$ & 11,87 & $\pm 2,38$ & 12,68 & $\pm 1,19$ & 12,12 & $\pm 2,80$ \\
\hline PUFA n6 & 26,94 & $\pm 2,08^{b}$ & 15,02 & $\pm 4,83^{\mathrm{a}}$ & 29,31 & $\pm 1,20^{\mathrm{b}}$ & 21,77 & $\pm 7,05$ & 25,72 & $\pm 2,61$ & 27,11 & $\pm 8,12$ \\
\hline
\end{tabular}

${ }^{\mathrm{ab}}$ Letras diferentes denotam diferenças estatísticas $(\mathrm{P}<0,05)$ ao longo do ciclo anual para fêmeas. Valores abaixo de 0.1 não foram considerados. SAT, MUFA, PUFA, PUFAn6, E PUFAn3, são as somatórias dos ácidos graxos saturados, monoinsaturados, polinsaturados $n 6$, e polinsaturados $n 3$. 
A fração polar hepática (Tabela 1) mostrou maiores valores de MUFA $(p=0,042)$ nos animais maduros na comparação com os animais em repouso. Concomitantemente observa-se um padrão de diminuição de PUFA e PUFA n3 (PUFA- repouso $x$ maduro, $p=0,027$; PUFA $n 3$ - repouso $x$ vitelogênese $p=0,027$, repouso $x$ maduro $p=0,030$; vitelogênese $x$ maduro, $p=0,014$ ). Analisando-se a fração polar muscular (Tabela 2) observamos uma tendência (não estatística) de diminuição de PUFA com o decorrer da maturação, tendência que se concretizou em diferença estatística significativa para a classe ômega 3, na comparação entre animais em repouso e maduros $(p=0,045)$. A fração polar ovariana (Tabela 3 ) apresentou maiores valores de PUFA n6 para os animais em repouso comparação com animais maduros $(p=0,005)$. 0 tecido uterino (Tabela 4$)$ mostrou maiores valores de SAT para os animais em vitelogênese na comparação com repouso $(p=0,022)$ e maduro $(p=0,005)$, este padrão parece ter sido compensado por menores valores de PUFA e PUFA n6 para o estágio de vitelogênese na comparação com animais em repouso e maduro ( $p<0,05$ para todas as comparações).

\section{DISCUSSÃO}

Neste estudo foram analisados diferentes parâmetros fisiológicos que estão intimamente associados à reprodução. Os resultados demonstram que as fêmeas de $P$. falkneri apresentaram alterações no metabolismo de lipídeos e ácidos graxos ao longo do ciclo reprodutivo. Este é o primeiro estudo que abrange as diferentes variáveis fisiológicas (metabólicas e estruturais) que regulam a reprodução desta espécie (Figura 3).

\section{Lipídeos totais}

Lipídeos são as principais fontes de energia metabólica em elasmobrânquios e estão estreitamente ligadas às condições ambientais, como quantidade e qualidade de presas, ciclos biológicos da reprodução e migração (PETHYBRIDGE et al., 2014). Analisando-se os tecidos neste trabalho observamos que as concentrações hepáticas e uterinas se mantêm altas, chegando a ser 100 vezes maiores que a concentração no tecido muscular. A explicação para tais diferenças pode ser atribuída ao fato de que, ao contrário dos mamíferos e de muitos teleósteos, os elasmobrânquios são desprovidos de tecido adiposo, e o fígado é o principal local de armazenamento de lipídeos (BALLANTYNE, 1997), bem como um importante local de síntese deste substrato, além disso, os elasmobrânquios são famosos por apresentarem fígados grandes, com grandes massas hepáticas em comparação com os teleósteos e outros vertebrados (BALLANTYNE, 1997; BALLANTYNE et al., 2010; SPEERS-ROESCH et al., 2010). A não alteração das concentrações de lipídeos no tecido hepático é um sinal claro da grande capacidade de metabolização e encaminhamento dos substratos durante o ciclo reprodutivo desta espécie (SHERIDAN, 1994).

Adicionalmente, arraias da ordem Myliobatiformes apresentam histotrofia lipídica, isso é, os filhotes, após o consumo do saco vitelínico, se alimentam do histotrofo, um fluido lipídico produzido e liberado pelo trofonema das mães (HAMLETT et al., 1998), o que explica as concentrações elevadas do substrato lipídico no tecido uterino analisado. Sabe-se que o fluido uterino é produzido logo após a ovulação e continua a ser 
produzido até o parto (HAMLETT et al., 1993), para que esta produção ocorra a morfologia do órgão se transforma drasticamente durante a gestação, a vascularização aumenta, os capilares hipertrofiaram no início e no meio da gestação e gotas lipídicas se acumulam nas fossas glandulares no meio e no final da gestação (HAMLETT et al., 1993). Neste trabalho os lipídeos totais uterinos mostram maiores concentrações no período maduro, em que as fêmeas estão preparadas para a produção do leite uterino, que nutrirá os filhotes.

\section{Perfil de ácidos graxos}

De forma geral, os ácidos graxos têm papel diferenciado no metabolismo dos vertebrados, os fosfolipídeos (lipídeos polares) são importantes constituintes de membranas e funcionam como o principal precursor de prostaglandinas, tromboxanos e leucotrienos, enquanto os triacilgliceróis (lipídeos neutros) servem como depósitos para ácidos graxos que são catabolizados no metabolismo energético celular (NELSON et al., 2012).

Os lipídeos armazenados sob a forma de triacilgliceróis são a principal reserva energética rápida na maioria dos vertebrados (SHERIDAN, 1994). Em geral, esses compostos são formados por dois SAT ou MUFA e uma cadeia central de PUFA. Assim, sabe-se que aproximadamente $80 \%$ da composição dos triacilgliceróis correspondem aos ácidos graxos saturados e monoinsaturados (BELL et al., 1986). Corroborando essas informações, a composição de ácidos graxos de todos os tecidos analisados em fêmeas adultas de $P$. falkneri apresentaram maiores porcentagens de SAT e MUFAs do que PUFAs (Tabelas 1 a 4).

Foi observado um padrão de aumento de ácidos graxos saturados na fração neutra do tecido hepático e uterino no estágio maduro, em comparação com o estágio de inatividade reprodutiva dos animais (repouso), este padrão parece refletir a preparação destes tecidos para o cuidado parental, já que o tecido hepático irá encaminhar suprimentos para o tecido uterino, que é responsável por grande parte do aporte energético dos filhotes, com a liberação do leite uterino (TOCHER, 2003; ARISTIZABAL, 2007; NARVÁEZ et al., 2008; PETHYBRIDGE et al., 2014;). Pethybridge et al. (2014) estudando tubarões brancos (Carcharodon carcharias), mostrou que lipídeos musculares e hepáticos são extremamente relacionados ao sucesso reprodutivo em elasmobrânquios.

Os vertebrados de modo geral requerem os PUFAs para um crescimento e desenvolvimento normal, incluindo a reprodução. Esses AGs atuam na reprodução influenciando nos padrões de desenvolvimento gonadal, na qualidade dos ovos, na fecundidade e na taxa de sobrevivência dos filhotes (IZQUIERDO et al., 2001; HUANG et al., 2003). Deste modo é esperado que ocorram alterações no perfil de ácidos graxos, mais especificamente os PUFA, nos diferentes tecidos de reserva ao longo do ciclo reprodutivo de fêmeas, como visto no presente trabalho, em que foram observadas diminuição de PUFAn3 no tecido hepático no período maduro, PUFA n6 no tecido muscular e PUFA total nos tecidos muscular e ovariano comparando-se o período de inatividade (repouso) e o período maduro para os três tecidos. Alternativamente, o tecido uterino mostrou aumento significativo de PUFA e PUFA n6 no período maduro, o que mostra a mobilização desta classe lipídica ao tecido uterino, denotando a transferência materno-fetal de suprimentos energéticos e 
estruturais para os filhotes durante a gestação, padrão observado na espécie vivípara Rhinoptera bonasus (RANGEL et al., 2020).

\section{CONCLUSÕES}

Os resultados suportam a hipótese de que a estratégia histotrófica lipídica de Myliobatiformes, mostrando aparente armazenamento de lipídeos no tecido uterino durante a maturação dos animais, culminando nos maiores valores amostrados no período maduro. Os tecidos uterino e hepático apresentaram concentrações até 100 vezes superiores de lipídeos na comparação com o tecido muscular e ovariano, corroborando o papel armazenados deste substrato nestes tecidos. O perfil de ácidos graxos mostrou um padrão de mobilização de ácidos graxos dos tecidos hepático e muscular para o tecido uterino, notadamente para ácidos graxos polinsaturados (totais, ômega 3 e ômega 6) importantes no desenvolvimento de embriões e juvenis. A Figura 3 mostra a compilação de todos os resultados analisados neste trabalho.

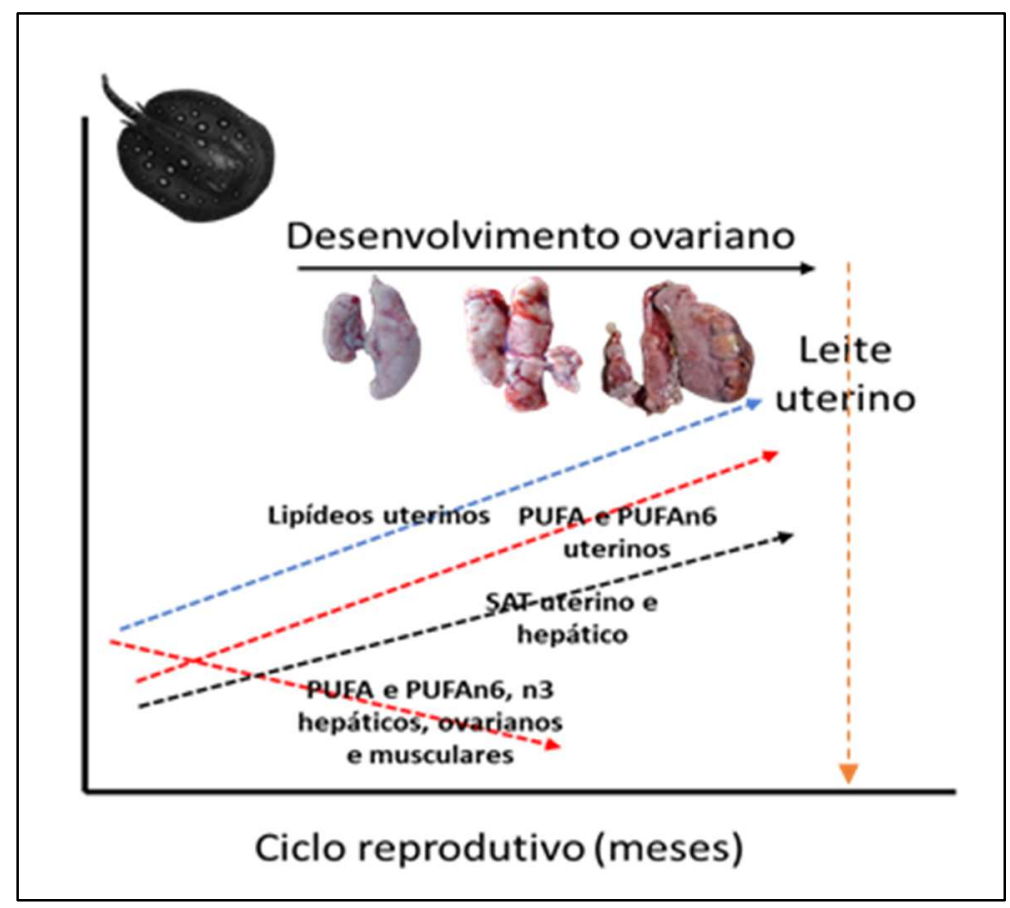

Figura 3: Figura conceitual das alterações lipídicas e de maturação gonadal de arraias de água doce (Potamotrygon falkneri), integrando todas as respostas observadas no presente estudo.

AGRADECIMENTOS: Fundação de Amparo à Pesquisa do Estado de São Paulo, bolsa de iniciação científica: 2016/11736-6 de Lucas Spada. Guarda Municipal da Ilha Solteira pela parceria, especialmente o Secretário de Segurança e trânsito Renato Augusto Alves, Luiz Arnaldo Leonaldo e Fabiano Gavoti da Silva.

\section{REFERÊNCIAS}

ARISTIZABAL, E. O.. Energy investment in the annual reproduction cycle of female red porgy, Pagrus pagrus (L.). Marine Biology, v.152, n.3, p.713-724, 2007. DOI: https://doi.org/10.1007/s00227-007-0729-6

BALLANTYNE, J. S.. Jaws: the inside story. The metabolism of elasmobranch fishes. Comparative
Biochemistry and Physiology, v.118, n.4, p.703-742, 1997. https://doi.org/10.1016/S0305-0491(97)00272-1

BALLANTYNE, J. S.; ROBINSON, J. W.. Freshwater elasmobranchs: A review of their physiology and biochemistry. Journal of Comparative Physiology, v.180, n.4, p.475-493, 2010. DOI: https://doi.org/10.1007/s00360$\underline{010-0447-0}$ 
BELL, M. V.; HENDERSON, R. J.; SARGENT, J. R.. The role of polyunsaturated fatty acids in fish. Comparative Biochemistry and Physiology, v.83, n.4, p.711-719, 1986. DOI: https://doi.org/10.1016/0305-0491(86)90135-5

CARRIER, J. C.; PRATT, H. L. J.; CASTRO, J. I.. Reproductive biology of elasmobranchs. In CARRIER, J. C.; MUSICK, J. A.; HEITHAUS, M. R.. Biology of sharks and their relatives. Boca Raton: CRC Press, 2004. p.269-286.

CARVALHO, M. R.; LOVEJOY, N. R.; ROSA, R. S.. Family Potamotrygonidae (river stingrays). In REIS, R.E.; KULLANDER, S. O.; FERRARIS, C. J.. Check List of the Freshwater Fishes of South and Central America. Porto Alegre: EDIPUCRS, 2003. p.22-28.

CHARVET-ALMEIDA, P.; GÓES DE ARAÚJO, M. L.; ALMEIDA, M. P.. Reproductive aspects of freshwater stingrays (Chondrichthyes: Patamotrygonidae) in the Brazilian Amazon Basin. Journal of Northwest Atlantic Fishery, v.35, p.165171, 2005. DOI: https://doi.org/10.2960/J.v35.m502

FOLCH, J.; LESS, M.; SLOANE STANLEY, G. H.. A simple method for the isolation and purification of total lipids from animal tissues. Journal of Biological Chemistry, v.226, p.497509, 1957.

FRINGS, C. S.; FENDLY, T. W.; DUNN, R. T.; QUENN, C. A.. Improved determination of total lipids by the sulphophospho-vanilin reaction. Clinical Chemistry, v.18, n.7, p.673-674, 1972. DOI: https://doi.org/10.1093/clinchem/18.7.673

GAMA, C. S.. Diversidade e ecologia das raias de água doce (Chondrichthyes: Potamotrygonidae) da Reserva Biológica do Parazinho, AP. Tese (Doutorado em Ciências Biológicas) Universidade Federal da Paraíba, João Pessoa, 2013.

GARRONE NETO, D.; HADDAD JUNIOR, V.; VILELA, M. J. A.; UIEDA, V. S.. Registro de ocorrência de duas espécies de potamotrigonídeos na região do Alto Rio Paraná e algumas considerações sobre sua biologia. Biota Neotropica, v.7, n.1, 2007. DOI: https://doi.org/10.1590/S167606032007000100023

HAMLETT, W. C.; EULITT, A. M.; JARRELL, R. L.; KELLY, M. A.. Uterogestation and placentation in elasmobranchs. Journal of Experimental Zoology India, v.266, p.347-367, 1993. DOI: https://doi.org/10.1002/jez.1402660504

HAMLETT, W.; HYSELL, M. K.. Uterine specializations in elasmobranchs. Journal of Experimental Zoology, v.282, p.438-459, 1998. DOI: https://doi.org/10.1002/(SICI)1097010X(199811/12)282:4/5<438::AID-JEZ4>3.0.CO;2-6

HUANG, C.-H.; LIANG, M.-F.; KAM, Y. C.. The fatty acid composition of oophagous tadpoles (Chirixalus eiffingeri) fed conspecific or chicken egg yolk. Comparative Biochemistry and Physiology, v.135, n.2, p.329-336, 2003. DOI: https://doi.org/10.1016/s1095-6433(03)00082-5

IZQUIERDO, H.; TACON, A. G. J.. Effect of broodstock nutrition on reproductive performance of fish. Aquaculture, v.197, p.25-42, 2001. DOI: https://doi.org/10.1016/S00448486(01)00581-6
KITSON, G.; LARSEN, B. S.; MCEWEN, C. N.. Gas

Chromatography and Mass Spectrometry: A Practical Guide. San Diego: Academic Press, 1996.

LASSO, C. A.; ROSA, R.; MORALES-BETNACOURT, M. A.; GARRONE-NETO, D.; CARVALHO, M. R.. XV. Rayas de Agua Dulce (Potamotrygonidae) de Suramérica. Parte II Colombia, Brasil, Perú, Bolivia, Paraguay, Uruguay y Argentina. Bogotá: Instituto de Investigación de Recursos Biológicos Alexander von Humboldt (IAvH), 2016.

LOVEJOY, N. R.. Systematics of myliobatoid elasmobranchs: with emphasis on the phylogeny and historical biogeography of neotropical freshwater stingrays (Potamotrygonidae: Rajiformes). Zoological Journal of the Linnean Society, v.117, n.3, p.207-257, 1996. DOI:

https://doi.org/10.1111/j.1096-3642.1996.tb02189.x

MARUSKA, K. P.; GELSLEICHTER, J.. Hormones and Reproduction in Chondrichthyan Fishes. In NORRIS, D. O.; LOPEZ, K. H.. Hormones and Reproduction of Vertebrates. Cambridge: Academic Press, 2011. p.209-237. DOI: https://doi.org/10.1016/B978-0-12-375009-9.10011-6

NARVÁEZ, M.; FREITES, L.; GUEVARA, M.; MENDOZA, J.; GUDERLEY, H.; LODEIROS, C. J.; SALAZAR, G.. Food availability and reproduction affects lipid and fatty acid composition of the brown mussel, Perna perna, raised in suspension culture. Comparative Biochemistry and Physiology, v.149, n.2, p.293-302, 2008. DOI: https://doi.org/10.1016/j.cbpb.2007.09.018

NELSON, D. L.; COX, M. M.. Lehninger Principles of Biochemistry. 6 ed. United States: W. H. Freeman, 2012.

PARRISH, C. C.. Lipid Biogeochemistry of plankton, settling matter and sediments in Trinity Bay, Newfoundland. I. Lipid classes. Organic Geochemistry, v.29, n.5-7, p.1531-1545, 1998. DOI: https://doi.org/10.1016/S0146-6380(98)00176-4

PEDREROS-SIERRA, T.; ARRIETA-PRIETO, D. M.; MEJÍA-FALLA, P. A.. Reproductive system of females of the Magdalena river endemic stingray Potamotrygon magdalenae: Anatomical and functional aspects. Journal of Morphology, v.277, n.5, p.680-697, 2016. DOI: https://doi.org/10.1002/jmor.20527

PETHYBRIDGE, H. R.; PARRISH, C. C.; BRUCE, B. D.; YOUNG, J. W.; NICHOLS, P. D.. Lipid, Fatty acid and energy density profiles of white sharks: insights into the feeding ecology and ecophysiology of a complex top predator. PLOS ONE, v.9, n. 5, p.e97877, 2014. DOI: https://doi.org/10.1371/journal.pone.0097877

RANGEL, B. S.; HUSSEY, N. E.; NIELLA, Y.; MARTINELLI, L. A.; GOMES, A. D.; MOREIRA, R. G.. Neonatal nutritional strategy of a viviparous elasmobranch with extremely low reproductive output. The Marine Ecology Progress Series, v.638, p.107-121, 2020. DOI: https://doi.org/10.3354/meps13261

SHERIDAN, M. A.. Regulation of lipid metabolism in poikilothermic vertebrates. Comparative and Biochemistry Physiology, v.107, n.4, p.495-508, 1994. DOI: https://doi.org/10.1016/0305-0491(94)90176-7

SPEERS-ROESCH, B.; TREBERG, J. R.. The unusual energy 
metabolism of elasmobranch fishes. Comparative Biochemistry and Physiology, v.155, n.4, p.417-434, 2010. DOI: https://doi.org/10.1016/i.cbpa.2009.09.031

SILVA, M. I.; OLIVEIRA, M. I. B.; COSTA, O. T. F.; DUNCAN, W. $P$.. Morphology and morphometry of the ovaries and uteri of the amazonian freshwater stingrays (Potamotrygonidae: Elasmobranchii). The Anatomical Record, v.300, n.2, p.265276, 2017. DOI: https://doi.org/10.1002/ar.23501

TOBERGTE, D. R.; CURTIS, S.. Uterine fluid and serum protein composition and serum steroid hormone concentrations during gestation in the aplacental viviparous Atlantic stingray, Dasyatis sabina. Journal of Chemical Information and Modeling, v.53, n.9, p.1689-1699, 2013. DOI: https://doi.org/10.1017/CB09781107415324.004

TOCHER, D. R.. Metabolism and Functions of Lipids and Fatty Acids in Teleost Fish. Reviews in Fisheries Science, v.11, n.2, p.107-184, 2003. DOI: https://doi.org/10.1080/713610925

YANG, Z.. Development of gas chromatographic method for profiling neutral lipids in marine samples. Dissertação (Mestrado em Química) - Memorial University of Newfoundland, Newfoundland, 1995.

A CBPC - Companhia Brasileira de Produção Científica (CNPJ: 11.221.422/0001-03) detém os direitos materiais desta publicação. Os direitos referem-se à publicação do trabalho em qualquer parte do mundo, incluindo os direitos às renovações, expansões e disseminações da contribuição, bem como outros direitos subsidiários. Todos os trabalhos publicados eletronicamente poderão posteriormente ser publicados em coletâneas impressas sob coordenação da Sustenere Publishing, da Companhia Brasileira de Produção Científica e seus parceiros autorizados. Os (as) autores (as) preservam os direitos autorais, mas não têm permissão para a publicação da contribuição em outro meio, impresso ou digital, em português ou em tradução. 